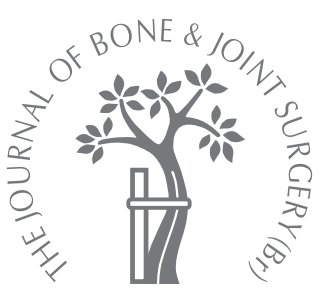

A. J. Hart, J. A. Skinner, P. Winship, N. Faria, E. Kulinskaya, D. Webster, S. Muirhead-Allwood, C. H. Aldam, H. Anwar, J. J. Powell

From Imperial College, London, England

A. J. Hart, FRCSG(Orth) Clinical Senior Lecturer \& Clinical Senior Lecturer \& Surgeon

Department of Musculoskeleta Departmer

Surger

Charing Cross)

E. Kulinskaya, PhD, Director Statistical Advisory Service (South Kensington) Imperial College, Fulham Palace Road, London SW7 2AZ, UK.

- J. A. Skinner, FRCS(Orth), Consultant Orthopaedic Surgeon S. Muirhead-Allwood, FRCS, Consultant Orthopaedic Surgeon Department of Orthopaedics Royal National Orthopaedic Hospital, Brockley Hill, Stanmore HA7 4LP, UK.

P. Winship, PhD, Senior Analyst N. Faria, PhD, Research Scientist

J. J. Powell, PhD, Head of the J. J. Powell, PhD, Head of the Micronutrient Status Research Section

Medical Research Council Human Nutrition Research Centre, Elsie Widdowson Laboratory, Fulbourn Road, Cambridge CB1 9NL, UK.

D. Webster, MRCP, Consultant

in Clinical Immunology
Royal Free Hospital, Pound Street, R.

C. H. Aldam, FRCS, Consultant Orthopaedic Surgeon

H. Anwar, BMedSci, MRCS, Orthopaedic Specialist Registrar Princess Alexandra Hospital NHS Trust, Hamstel Road, Harlow CM20 10X, UK.

Correspondence should be sent to Mr A. J. Hart; e-mail: a.hart@imperial.ac.uk

(C2009 British Editorial Society of Bone and Joint Surgery doi:10.1302/0301-620X.91B6. $21844 \$ 2.00$

$J$ Bone Joint Surg $[\mathrm{Br}]$ 2009:91-B:835-42. Received 29 September 2008 Accepted after revision 19 Accepted after revision 19 February 2009

\title{
Circulating levels of cobalt and chromium from metal-on-metal hip replacement are associated with $\mathrm{CD}^{+} \mathrm{T}$-cell lymphopenia
}

\begin{abstract}
We carried out a cross-sectional study with analysis of the demographic, clinical and laboratory characteristics of patients with metal-on-metal hip resurfacing, ceramic-onceramic and metal-on-polyethylene hip replacements. Our aim was to evaluate the relationship between metal-on-metal replacements, the levels of cobalt and chromium ions in whole blood and the absolute numbers of circulating lymphocytes. We recruited 164 patients (101 men and 63 women) with hip replacements, 106 with metal-on-metal hips and 58 with non-metal-on-metal hips, aged $<65$ years, with a pre-operative diagnosis of osteoarthritis and no pre-existing immunological disorders.

Laboratory-defined T-cell lymphopenia was present in 13 patients (15\%) (CD8 ${ }^{+}$ lymphopenia) and 11 patients (13\%) (CD3 ${ }^{+}$lymphopenia) with unilateral metal-on-metal hips. There were significant differences in the absolute $C D 8^{+}$lymphocyte subset counts for the metal-on-metal groups compared with each control group ( $p$-values ranging between 0.024 and 0.046 ). Statistical modelling with analysis of covariance using age, gender, type of hip replacement, smoking and circulating metal ion levels, showed that circulating levels of metal ions, especially cobalt, explained the variation in absolute lymphocyte counts for almost all lymphocyte subsets.
\end{abstract}

New technology has led to a dramatic increase in the use of metal-on-metal (MOM) hip replacement and resurfacing, so that in the United Kingdom it has become the most commonly used type of procedure for those patients with osteoarthritis who are $<60$ years of age. ${ }^{1,2}$ Approximately 50000 patients worldwide have had the latest type of MOM replacement in the last three years, but the rate of increase in countries such as the United States is projected to be $100 \%$ per annum since the Food and Drug Administration (FDA) approved the use of two of these devices in $2006^{3}$ and $2007 .^{4}$ The FDA approval is provisional, subject to prospective monitoring of the blood levels of cobalt (Co) and chromium $(\mathrm{Cr})$, which is typically tenfold greater than in normal healthy individuals, and has been linked to DNA damage of lymphocytes. ${ }^{5}$ In a pilot study, we observed lower peripheral lymphocyte counts in patients with MOM hip replacement compared with a group with metal-onpolyethylene (MOP) articulations. ${ }^{6}$

In this study we describe the levels of Co and $\mathrm{Cr}$ ions in whole blood and the lymphocyte subsets (total, $\mathrm{CD}^{+}, \mathrm{CD}^{+}, \mathrm{CD}^{+}, \mathrm{CD}^{2} 9^{+}, \mathrm{CD} 16^{+}$) of a large series of patients with either MOM or ceramic-on-ceramic (COC) hip replacement.
The data were also compared with the results from our previous report on MOP hip replacement. ${ }^{6}$ Our aims were to determine whether the finding of reduced T-lymphocyte counts in patients with MOM hip replacement was repeatable when an unstudied series of such patients was compared with those with COC or MOP hips, to explore the influence of potential confounding factors including age, smoking, gender and time since operation and to establish whether circulating Co and/or Cr levels were related to any differences in lymphocyte counts.

\section{Patients and Methods}

Our study included consenting, consecutive patients resident in the South East of England, and were therefore easier to recall, who were aged $<65$ years and who had received a successful hip replacement between January 2003 and January 2005, following the diagnosis of osteoarthritis in one or both hips, at our institutions. We recruited 100 patients with unilateral MOM hip replacement, 25 with bilateral MOM hip replacement, 34 with MOP and 25 with COC hip replacements. The study was approved by the ethics committee of the Royal National Orthopaedic Hospital. 
We excluded patients with known causes of reduced blood lymphocyte counts such as those receiving cytotoxic or immunosuppressive therapy, previous high-dose radiation, chronic infection such as HIV and environmental immunotoxicity. With regard to factors which might influence the blood level of Co and Cr, we excluded patients if they had been exposed to these metals from other sources, for example, from other hip implants or plates, from inhalation in metal foundries or from drugs such as unusual dietary supplements. Applying these criteria resulted in the exclusion of 12 unilateral and seven bilateral MOM hip patients. There were no COC patients excluded. One MOP patient was excluded because the blood sample had been lost. This last group of patients was from our previously published study, ${ }^{6}$ but all the blood samples were reanalysed for metal levels, using more advanced techniques. The final numbers of hip replacements in each group were 88 unilateral MOM, 18 bilateral MOM, 25 unilateral COC and 33 unilateral MOP.

We recorded whether patients smoked, ${ }^{7}$ which is known to stimulate macrophages and increase the $\mathrm{CD}^{+}$count, their age ${ }^{8}$ and gender. ${ }^{9}$ In addition, because of a reported small effect of seasonal ${ }^{10}$ and circadian ${ }^{11}$ variation on the lymphocyte count, blood was collected within the same two-hour period in the morning throughout the months of February and March.

There were also factors which might affect the rate of wear of hip replacements which, in the case of MOM hips, might also affect blood metal levels. These could be grouped into patient-related factors such as activity, ${ }^{12}$ implant factors including the design and materials ${ }^{13}$ and the 'bedding-in' phase during which there is high wear, ${ }^{14}$ and surgical factors such as the position of the components. ${ }^{15,16}$ The effects of implant factors were reduced by excluding patients in whom the replacement had been performed less than six months previously thereby avoiding the highwearing, bedding-in phase, and including only one type of hip replacement for each group. These were as follows: MOM, the Birmingham Hip Resurfacing (Smith \& Nephew, Warwick, United Kingdom) with both bearing surfaces made from American Standard Testing Materials (ASTM) F75 Co-Cr; COC, the Exeter (Stryker, Newbury, United Kingdom) femoral stem (stainless steel) and ABG acetabular component (Stryker) with alumina ceramicbearing surfaces (CeramTec, Plochingen, Germany); and MOP, Co-Cr ASTM F75 femoral head and polyethylene acetabular component (Biomet, Bridgend, United Kingdom) and Depuy, Leeds, United Kingdom with the Stanmore femoral component (Biomet).

The unilateral MOM group was considerably larger than the 34 hips presented in our previous study. ${ }^{6}$ Power calculations were used to determine the size of the bilateral MOM and COC groups. We assumed that patients with a COC replacement would have a similar T-cell count to those with a MOP replacement or a healthy control group, and that the bilateral MOM patients would have a reduced
T-cell count in comparison with unilateral MOM patients. Detection of the difference of 0.3 in log-transformed T-cell counts with an SD of 0.4 in each group was seen in our original study ${ }^{6}$ between the MOM and the MOP patients using a two-sample two-sided $t$-test at a level of significance of $5 \%$ and given a $3: 1$ allocation ratio, required 24 patients $(18)$ in the smaller group to achieve a power of $90 \%(80 \%)$.

Demographic and clinical data were collected from the patients' notes and outpatient consultations. We defined a smoker as any patient who had smoked within the preceding three months. Blood samples were taken using a plastic cannula to avoid metal contamination from the needle.

Analysis of $\mathrm{Co}$ and $\mathrm{Cr}$. Samples were analysed at the MRC Human Nutrition Research Unit (Cambridge, United Kingdom) for the level of Co and Cr in whole blood according to a recently validated method ${ }^{17}$ using inductively-coupled plasma mass spectrometry (Perkin Elmer Elan+ 6100, Perkin Elmer, Waltham, Massachusetts). Homogeneity of the sample solutions was ensured by the appropriate preparation of samples and gentle agitation immediately before analysis. A double-type spray chamber (Perkin Elmer) and wide-bore V-groove nebuliser (Jobin Yvon Horiba Ltd, Stanmore, United Kingdom) were used. The rate of flow for aspiration of the samples was $0.9 \mathrm{ml} / \mathrm{min}$. A dynamic reaction cell gas of argon and 5\% hydrogen was used for analysis of $\mathrm{Cr}$ but not for Co. Three different Seronorm (Stasjonsveien, Billingstad, Norway) whole-blood-certified reference materials, showing low, moderate and high levels of Co and Cr, were used to prepare calibration curves and as quality controls within batches of samples. Samples were analysed in seven separate batches over a period of five weeks. Samples were analysed blindly but we ensured that each batch contained a representative number of samples from each group of patients. The samples from the previously reported MOP group ${ }^{6}$ were re-analysed with the batches and only the new analytical data were used. The total levels of the metal ions were measured.

Analysis of lymphocyte populations. A standard method was used, involving lymphocyte staining with monoclonal antibodies and counting using a fluorescence-activated cell sorter (FACS) at the Royal Free Hospital (London, United Kingdom). This had two laser beams allowing the use of four-colour staining. The monoclonal antibodies used recognised the following populations: T-cells $\left(\mathrm{CD}^{+}\right)$, T-helper cells $\left(\mathrm{CD}^{+}\right)$, T-cytotoxic cells $\left(\mathrm{CD} 8^{+}\right)$, B-cells $\left(\mathrm{CD} 19^{+}\right)$and natural killer cells $\left(\mathrm{CD} 16^{+}, \mathrm{CD} 56^{+}\right)$.

Statistical analysis. The data on the lymphocyte counts and Co and Cr levels were skewed with many outliers. Therefore we determined statistical significance using nonparametric methods such as the Kruskal-Wallis test for continuous variables, and the chi-squared test for categorical variables. This allowed assessment as to whether the two MOM groups or the two non-MOM (COC and MOP) groups could be pooled together. Pair-wise comparisons of lymphocyte numbers using the two-sided Mann-Whitney U test were used to determine which lymphocyte subtypes 


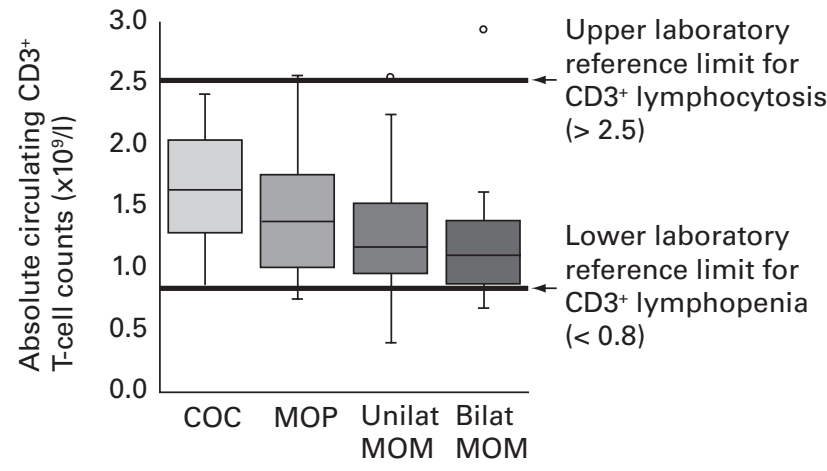

Fig. 1

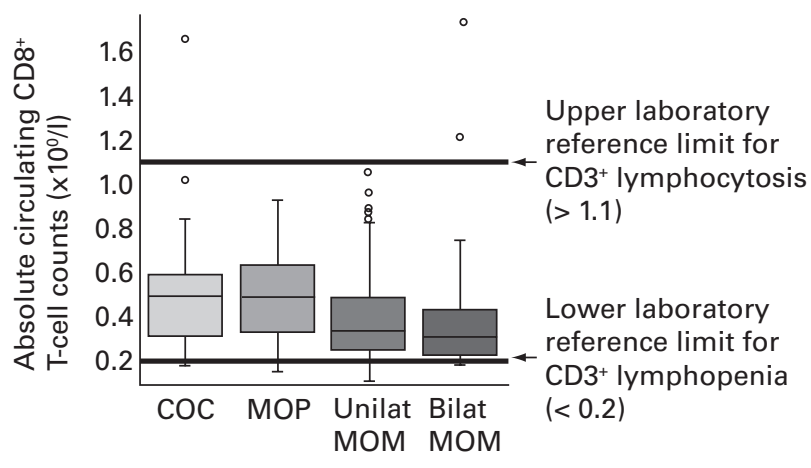

Fig. 2

Box plot of $\mathrm{CD}^{+} \mathrm{T}$-cell counts against the type of hip replacement. Variable means and the upper and lower limits of the laboratory reference range are shown (COC, ceramic-on-ceramic; MOP, metal-on-polyethylene; MOM; metal-on-metal).

Box plot of $\mathrm{CD} 8^{+} \mathrm{T}$-cell counts against the type of hip replacement. Variable means and the upper and lower limits of the laboratory reference range are shown (COC, ceramic-on-ceramic; MOP, metal-on-polyethylene; MOM; metal-on-metal).

Table I. Details of the results giving the median (interquartile range) for continuous, and the number and percentage for categorical variables

\begin{tabular}{|c|c|c|c|c|c|c|}
\hline & Overall $(n=164)$ & $\operatorname{MOP}^{*}(n=33)$ & $\operatorname{coc}^{\dagger}(n=25)$ & $\begin{array}{l}\text { Unilateral } \mathrm{MOM}^{\ddagger} \\
(\mathrm{n}=\mathbf{8 8})\end{array}$ & $\begin{array}{l}\text { Bilateral MOM } \\
(n=18)\end{array}$ & p-value ${ }^{\S}$ \\
\hline \multicolumn{7}{|l|}{ Gender (\%) } \\
\hline $\mathrm{F}$ & $63(38)$ & $14(42)$ & $16(64)$ & $26(30)$ & 7 (39) & 0.016 \\
\hline M & $101(62)$ & $19(58)$ & $9(36)$ & $62(70)$ & $11(61)$ & \\
\hline Smoking (\%) & $23(14)$ & $9(27)$ & $7(28)$ & $4(5)$ & $3(17)$ & 0.002 \\
\hline Age in yrs (range) & 58 (51 to 63 ) & 64 (55 to 67$)$ & 59 (54 to 60$)$ & $56(51$ to 61$)$ & 56 (51 to 61 ) & 0.004 \\
\hline Body mass index $\left(\mathrm{kg} / \mathrm{m}^{2}\right)$ & 26 (24 to 29 ) & 28 (26 to 28 ) & 26 (25 to 33$)$ & 26 (23 to 28$)$ & 25 (23 to 27 ) & 0.003 \\
\hline Months after surgery & 37 (25 to 48 ) & 25 (18 to 20$)$ & 25 (20 to 33$)$ & 43 (37 to 52 ) & 29 (24 to 34$)$ & $<0.001$ \\
\hline Cobalt (parts per billion) & 1.29 (0.49 to 2.01$)$ & $0.44(0.32$ to 0.748$)$ & $0.21(0.17$ to 0.25$)$ & 1.71 (1.29 to 2.33$)$ & 2.45 (1.56 to 4.30$)$ & $<0.001$ \\
\hline Chromium (parts per billion) & 1.77 (0.63 to 2.61$)$ & $0.65(0.21$ to 1.10$)$ & $0.32(0.24$ to 0.45$)$ & 2.33 (1.79 to 2.91$)$ & 2.35 (1.70 to 3.36$)$ & $<0.001$ \\
\hline Total lymphocyte count $\left(\times 10^{9} / \mathrm{I}\right)$ & 1.77 (1.52 to 2.24$)$ & 1.76 (1.53 to 2.51$)$ & 2.15 (1.76 to 2.65$)$ & $1.76(1.48$ to 2.15$)$ & 1.6 (1.30 to 1.86$)$ & 0.004 \\
\hline $\mathrm{CD}^{+}$count $\left(\times 10^{9} / \mathrm{I}\right)$ & 1.28 ( 1.00 to 1.63$)$ & 1.37 (1.01 to 1.79 ) & 1.65 (1.29 to 2.07$)$ & 1.12 (0.86 to 1.39$)$ & $1.12(0.86$ to 1.39$)$ & 0.001 \\
\hline $\mathrm{CD}^{+}\left(\times 10^{9} / \mathrm{I}\right)$ & $0.82(0.63$ to 1.12$)$ & $0.8(0.62$ to 1.1$)$ & $1.16(0.82$ to 1.37$)$ & $0.80(0.62$ to 1.02$)$ & $0.81(0.63$ to 1.04$)$ & 0.007 \\
\hline $\mathrm{CD}^{+}\left(\times 10^{9} / \mathrm{I}\right)$ & 0.37 (0.27 to 0.57$)$ & 0.49 (0.32 to 0.64$)$ & $0.50(0.31$ to 0.65$)$ & $0.34(0.26$ to 0.49$)$ & $0.31(0.23$ to 0.46$)$ & 0.024 \\
\hline $\mathrm{CD}_{19}{ }^{+}\left(\times 10^{9} / \mathrm{I}\right)$ & $0.20(0.14$ to 0.29$)$ & 0.24 (0.14 to 0.33$)$ & $0.24(0.19$ to 0.42$)$ & 0.19 (0.13 to 0.28$)$ & $0.16(0.14$ to 0.20$)$ & 0.003 \\
\hline $\mathrm{CD}^{1} 6^{+}\left(\times 10^{9} / \mathrm{I}\right)$ & $0.29(0.19$ to 0.37$)$ & $0.31(0.19$ to 0.37$)$ & $0.25(0.18$ to 0.35$)$ & $0.31(0.21$ to 0.42$)$ & $0.20(0.13$ to 0.32$)$ & 0.038 \\
\hline
\end{tabular}

* MOP, metal-on-polyethylene

† COC, ceramic-on-ceramic

¥ MOM, metal-on-metal

$\S$ Kruskal-Wallis test for continuous variables and/or the chi-squared test for categorical variables

Median lymphocyte subset counts from other reported studies: Schaberg et $\mathrm{al}^{7}$ and Huppert et $\mathrm{al}^{8}$

differed between each pair of groups. We adjusted for potential confounders in a multivariate analysis of covariance (ANCOVA) model to determine the effect of the demographic, clinical and laboratory characteristics of the groups of patients. A p-value $\leq 0.05$ was assumed to be significant.

\section{Results}

Figures 1 and 2 and Tables I and II illustrate and quantify the intergroup differences. There were significant differences in the levels of metal ions in whole blood and in the absolute lymphocyte counts due mainly to $\mathrm{CD} 4^{+} / \mathrm{CD} 8^{+}$differences in the groups, as defined by the type of hip replacement. A total of ten patients of the 106 (9.4\%) with MOM hips had circulating levels of $\mathrm{Cr}$ which were greater than 5 parts per billion (ppb). The total lymphocyte and $\mathrm{CD}^{+}$ counts merely represented the sums of their sub-populations.

The median $\mathrm{CD}^{+}$counts (Table I) were markedly reduced in both the unilateral $(0.34)$ and bilateral MOM (0.31) groups when compared with the COC group (0.5), the MOP group (0.49) and data from the studies of Schaberg et $\mathrm{al}^{7}$ and Huppert et al. ${ }^{8}$ Laboratory-defined Tcell lymphopenia was present in 13 patients $(15 \%)\left(\mathrm{CD}^{+}\right.$ lymphopenia with absolute counts $<0.2 \times 10^{9} / 1$ and 11 patients $(13 \%)\left(\mathrm{CD} 3^{+}\right.$lymphopenia with absolute counts $\left.<0.8 \times 10^{9} / \mathrm{l}\right)$ with unilateral MOM hips. The only lymphocyte subtype which differed significantly when the uni- 
Table II. P-values (two-sided Mann-Whitney $U$ test) for pair-wise comparisons of circulating metal ion concentrations and absolute lymphocyte counts

\begin{tabular}{|c|c|c|c|c|c|c|}
\hline & $\begin{array}{l}\text { MOP }^{*} \text { vs unilateral } \\
\text { MOM }^{\dagger}\end{array}$ & MOP vs bilateral MOM & MOP vs $\mathrm{COC}^{\ddagger}$ & $\begin{array}{l}\text { Unilateral MOM } \\
\text { vs bilateral MOM }\end{array}$ & $\begin{array}{l}\text { Unilateral MOM } \\
\text { vs COC }\end{array}$ & $\begin{array}{l}\text { Bilateral MOM } \\
\text { vs COC }\end{array}$ \\
\hline Whole blood Co & 0.000 & 0.000 & 0.000 & 0.046 & 0.000 & 0.000 \\
\hline Whole blood $\mathrm{Cr}$ & 0.000 & 0.000 & 0.021 & 0.966 & 0.000 & 0.000 \\
\hline Total Iymphocyte count & 0.239 & 0.003 & 0.066 & 0.166 & 0.003 & 0.001 \\
\hline $\mathrm{CD}^{+}$count & 0.141 & 0.000 & 0.026 & 0.482 & 0.000 & 0.001 \\
\hline $\mathrm{CD}^{+}$count & 0.679 & 0.001 & 0.013 & 0.528 & 0.001 & 0.010 \\
\hline $\mathrm{CD}^{+}$count & 0.024 & 0.024 & 0.939 & 0.593 & 0.024 & 0.046 \\
\hline $\mathrm{CD}_{19}{ }^{+}$count & 0.101 & 0.005 & 0.326 & 0.156 & 0.005 & 0.001 \\
\hline $\mathrm{CD}_{16}{ }^{+}$count & 0.227 & 0.157 & 0.673 & 0.007 & 0.158 & 0.184 \\
\hline
\end{tabular}

* MOP, metal-on-polyethylene

† MOM, metal-on-metal

¥ COC, ceramic-on-ceramic

lateral MOM cohort was compared with both non-MOM comparison groups (MOP and COC) was $\mathrm{CD}^{+}(\mathrm{p}=0.024$ and $\mathrm{p}=0.024$ for MOP and COC, respectively; Table II). The bilateral MOM cohort was also different for the CD $8^{+}$ count when compared with the COC $(p=0.046)$ and the MOP control group $(p=0.024)$ with additional differences for total lymphocytes $\mathrm{CD}^{+}, \mathrm{CD} 4^{+}$, and $\mathrm{CD} 19^{+}$.

The median $\mathrm{CD}^{+}$count was increased in the COC group when compared with all other groups (Table I), and historical data, ${ }^{7,8}$ which may be a confounding effect of smoking. This was found most frequently in the COC group and is known to increase the $\mathrm{CD} 4{ }^{+}$count. $^{7}$

The median value of the body mass index (BMI) of all groups was within the same category of overweight (BMI 25 to 30). There was a significant difference in age between the groups which probably reflects the current, widely used practice of implanting COC or MOM hips in patients aged $<65$ years and of MOP in those over 65 years $(\mathrm{p}=0.003$, chi-squared test). Similar differences in gender probably reflected the current practice of restricting MOM hip resurfacing in female patients to those aged $<55$ years, ${ }^{18}$ unless a bone mineral density scan is particularly favourable, because of the increased risk of fracture of the femoral neck in the resurfaced femoral head.

Accordingly, we incorporated factors such as age, gender, the type of hip replacement, smoking and circulating metal ion levels into our later ANCOVA statistical modelling to determine their effects on absolute lymphocyte numbers.

We transformed the lymphocyte subset counts logarithmically and undertook ANCOVA to determine whether differences in lymphocyte subset counts in the groups could be explained by differences in the type of hip replacement when adjusting for gender, months after surgery and smoking as potential confounding factors. We used lymphocyte subset counts as the dependent/outcome variable, with the type of hip replacement, gender and smoking as the factors, and months after surgery and age as covariates. Backward selection was used to reduce the final models to include only significant predictors. The

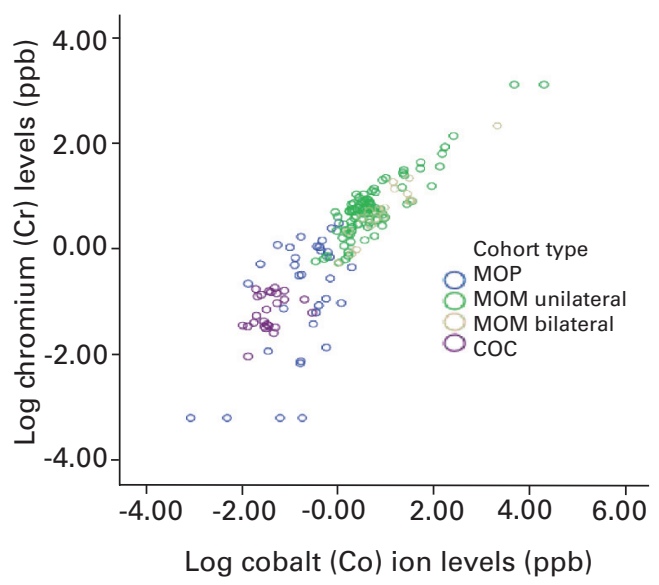

Fig. 3

Scatter plot of circulating metal ion levels in all patients showing log transformations of Co vs $\mathrm{Cr}$ ion levels (ppb, parts per billion) (MOP, metal-on-polyethylene; MOM, metalon-metal; $\mathrm{COC}$, ceramic-on-ceramic).

p-values from these final models are given below. The type of hip replacement was strongly predictive of all lymphocyte subset counts ( $p$-values varied between 0.003 for $\mathrm{CD} 19^{+}$and 0.046 for $\mathrm{CD} 16^{+}$), broadly in agreement with results of the Mann-Whitney U test shown in Table II. Months after surgery and age were not significant factors. Gender was significant for $\mathrm{CD}^{+}(\mathrm{p}=0.018)$ and $\mathrm{CD} 4^{+}$ $(\mathrm{p}=0.018)$. Smoking had a significant predictive effect only for the CD16 $6^{+}$count $(\mathrm{p}=0.024)$. Thus, the type of hip replacement was the most consistent factor for the differences in lymphocyte subset counts.

Having ascertained the differences in lymphocyte subset counts between the groups, we sought to explain the findings in relation to the circulating blood levels of metal ions. Those were highly correlated (Spearman correlation $0.892 ; \mathrm{p}<0.001)$. Figure 3 shows the distribution of both metals by the type of hip replacement (the four lowest blue points correspond to values below 0.05 , the limit of quan- 
Table III. Cobalt (Co) category by hip replacement

\begin{tabular}{|c|c|c|c|c|c|c|}
\hline Quartile group of Co & Cohort type & MOP $^{*}$ & Unilateral MOM$^{\dagger}$ & Bilateral MOM & coc $^{\ddagger}$ & Total \\
\hline \multirow[t]{2}{*}{1} & Count & 17 & 0 & 0 & 24 & 41 \\
\hline & $\%$ within cohort type & 51.5 & 0.0 & 0.0 & 96.0 & 25.0 \\
\hline \multirow[t]{2}{*}{2} & Count & 16 & 21 & 3 & 1 & 41 \\
\hline & $\%$ within cohort type & 48.5 & 23.9 & 16.7 & 4.0 & 25.0 \\
\hline \multirow[t]{2}{*}{3} & Count & 0 & 37 & 4 & 0 & 41 \\
\hline & $\%$ within cohort type & 0.0 & 42.0 & 22.2 & 0.0 & 25.0 \\
\hline \multirow[t]{2}{*}{4} & Count & 0 & 30 & 11 & 0 & 41 \\
\hline & $\%$ within cohort type & 0.0 & 34.1 & 61.1 & 0.0 & 25.0 \\
\hline Total & Count & 33 & 88 & 18 & 25 & 164 \\
\hline
\end{tabular}

Table IV. Chromium (Cr) category by hip replacement

\begin{tabular}{|c|c|c|c|c|c|c|}
\hline Quartile group of $\mathrm{Cr}$ & Cohort type & MOP* & 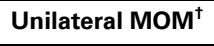 & Bilateral MOM & COC $^{\ddagger}$ & Total \\
\hline \multirow[t]{2}{*}{1} & Count & 16 & 0 & 0 & 25 & 41 \\
\hline & $\%$ within cohort type & 48.5 & 0.0 & 0.0 & 100.0 & 25.0 \\
\hline \multirow[t]{2}{*}{2} & Count & 16 & 20 & 5 & 0 & 41 \\
\hline & $\%$ within cohort type & 48.5 & 22.7 & 27.8 & 0.0 & 25.0 \\
\hline \multirow[t]{2}{*}{3} & Count & 1 & 34 & 6 & 0 & 41 \\
\hline & $\%$ within cohort type & 3.0 & 38.6 & 33.3 & 0.0 & 25.0 \\
\hline \multirow[t]{2}{*}{4} & Count & 0 & 34 & 7 & 0 & 41 \\
\hline & $\%$ within cohort type & 0.0 & 38.6 & 38.9 & 0.0 & 25.0 \\
\hline Total & Count & 33 & 88 & 18 & 25 & 164 \\
\hline
\end{tabular}

tification). In order to analyse further predictive factors for lymphocyte subset counts, we categorised patients by quartiles of metal ion levels (Tables III and IV).

Patients who had hips without $\mathrm{Co}$ or $\mathrm{Cr}$ in either bearing surface (COC group) had the lowest levels of metal ions in whole blood. MOP hips had the next highest levels, and the bilateral MOM hips had the highest (Fig. 4). Smoking was associated with low metal ion levels (Mann-Whitney U test, $p=0.005)$, but when adjusted for type of hip replacement this association disappeared. Thus, smoking was a confounder for metal levels because there was a greater frequency of smokers in the COC cohort (which had a low level of metal ions).

We undertook ANCOVA using lymphocyte subset counts as the dependent variable, categorised $\mathrm{Co}$ and $\mathrm{Cr}$ levels, gender and type of hip replacement as the factors and months after surgery and age as covariates. Neither age nor time after surgery was significant and they were there- fore excluded from the models. The final models given in Table V include only gender, Co category because this was marginally more predictive than $\mathrm{Cr}$ and the type of hip replacement. Women had higher lymphocyte counts. Co category was the most significant factor for the differences in lymphocyte subset counts (Fig. 5). The type of hip replacement was not significant after adjusting for gender and Co category.

\section{Discussion}

Our results showed that patients with MOM hips had reduced peripheral blood counts of T-lymphocytes in particular and B-lymphocytes when compared with control subjects with hip replacements which did not produce metal wear debris. All pair-wise comparisons of lymphocyte subset counts of any MOM cohort (either total, unilateral or bilateral) with both control cohorts (COC or MOP) revealed that the effect was consistent only for 


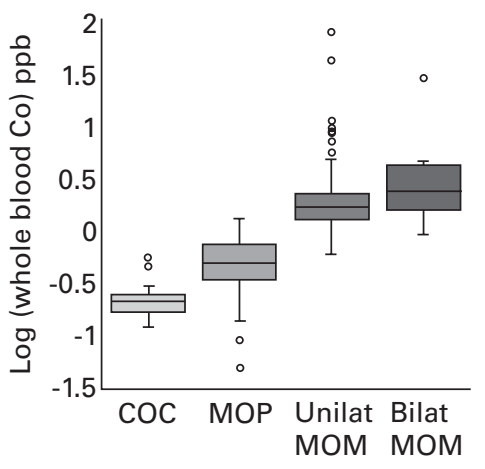

Fig. 4

Box plot of whole blood Co level vs type of hip replacement.(ppd, parts per billion; (COC, ceramic-on-ceramic; MOP, metalon-polyethylene; MOM, metal-on-metal).

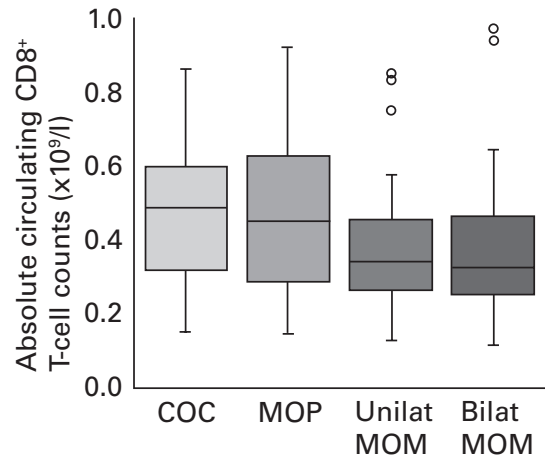

Fig. 5

Box plot of $\mathrm{CD}^{+}$T-lymphocyte counts vs whole blood Co category (COC, ceramic-onceramic; MOP, metal-on-polyethylene; MOM, metal-on-metal)

Table V. The final analysis of covariance statistical models for log lymphocyte subset counts. Cobalt (Co) category, type of hip replacement and gender are the only factors included in these models

\begin{tabular}{|c|c|c|c|c|c|c|}
\hline \multirow[b]{2}{*}{ Predictive factor } & \multicolumn{6}{|c|}{ Log lymphocyte subset counts } \\
\hline & CD16 & CD19 & $\mathrm{CD} 3$ & $\mathrm{CD} 4$ & CD8 & Total lymphocytes \\
\hline Gender & 0.787 & 0.312 & 0.018 & 0.018 & 0.141 & 0.022 \\
\hline Co category p-value* & 0.194 & 0.001 & 0.001 & 0.004 & 0.039 & 0.007 \\
\hline $\begin{array}{l}\text { Type of hip replacement } \\
\text { p-value* }\end{array}$ & 0.087 & 0.699 & 0.304 & 0.225 & 0.645 & 0.239 \\
\hline $\begin{array}{l}\text { Correlation coefficient } \\
\left(R^{2}\right)(\text { adj })\end{array}$ & 0.027 & 0.073 & 0.112 & 0.094 & 0.032 & 0.085 \\
\hline $\begin{array}{l}\text { Significant differences } \\
\text { in Co categories }\end{array}$ & & $\begin{array}{l}1 \text { to } 2, p=0.020 \\
1 \text { to } 3, p=0.001 \\
1 \text { to } 4, p=0.017\end{array}$ & $\begin{array}{l}1 \text { to } 3, p<0.001 \\
1 \text { to } 4, p=0.065\end{array}$ & 1 to $3, p=0.002$ & 1 to $3, p=0.070$ & 1 to $3, p=0.004$ \\
\hline
\end{tabular}

$\mathrm{CD} 8^{+}$T-lymphocytes. Since $\mathrm{CD} 3^{+}$cells are largely $\mathrm{CD} 4^{+}$ plus $\mathrm{CD} 8^{+}$, the differences in the $\mathrm{CD}^{+}$count between cohorts may have been predominantly due to differences in the $\mathrm{CD} 8^{+}$count. We found that, when all the patients were analysed together, the level of Co or Cr (both constituents of the wear debris from MOM hips) in the blood inversely correlated with the absolute counts of T- and B-lymphocytes.

In a small previous study, we reported a reduction of $30 \%$ in the $\mathrm{CD}^{+}{ }^{+}$T-cell count in peripheral blood in patients with MOM hips when compared with those with MOP hips. ${ }^{6}$ This observation was confirmed in this follow-up study using larger numbers of patients and two different groups, both with different non-MOM bearings, for comparison.

Moreover, unlike before, this study was designed to minimise the effect of potential confounding variables, known to influence lymphocyte subset counts in healthy persons. These included infection, immunosuppressive medication, circadian variation, ${ }^{11}$ seasonal variation, ${ }^{10}$ smoking ${ }^{7}$ and gender. ${ }^{9}$ There were still some differences between the groups, but our statistical modelling allowed us to adjust for these and still show a statistically signifi- cant reduction of T-cell counts in MOM patients. In fact, for unilateral MOM patients, $11(13 \%)$ had $\mathrm{CD}^{+}$counts and $13(15 \%)$ had $\mathrm{CD} 8^{+}$counts which were below the lower laboratory reference ranges $\left(0.8\right.$ and $0.2 \times 10^{9} /$, respectively) used to define lymphopenia.

There are laboratory reference ranges for immunological tests, but there is some inter-laboratory variation, and therefore these cannot be wholly relied upon. Hence, we compared patient groups which differed only in the type of hip replacement. The robustness of our findings was therefore influenced by our control subjects, who showed similar median and interquartile ranges for lymphocyte subset numbers to those reported by other groups. ${ }^{8}$ Importantly, our study has shown that the lymphocyte count reduction may not be limited to CD8+ T-cells only, since there was also some reduction in CD19+ (B-cell) counts. This appeared to be related to the level of $\mathrm{Co}$ and $\mathrm{Cr}$ in whole blood, so that higher levels were associated with a reduction of both $\mathrm{CD} 8^{+}$and $\mathrm{CD} 19^{+}$counts.

One other study has reported absolute lymphocyte counts after hip replacement. ${ }^{19}$ It showed significant differences in total lymphocytes and CD16 $6^{+}$lymphocyte subsets, but not $\mathrm{T}$-cell subsets $\mathrm{CD} 3^{+}, \mathrm{CD}^{+}{ }^{+}$or $\mathrm{CD} 8^{+}$when 
22 patients with loose MOP hip replacements were compared with 20 healthy control subjects. In a more recent study the same authors reported lymphocyte subset counts from patients with the following types of hip replacement: MOM in 15, MOP in 13 and COC in $13 .{ }^{20}$ They found no differences in lymphocyte subset numbers in these groups. They did, however, find a reduction in T-cell lymphocyte counts when they compared either the MOM or MOP groups with a healthy control series. The patients' ages and time from operation were similar to those of our patients, but the small numbers in each group probably resulted in a study that was underpowered.

An important contribution of our present study was a demonstration of a close relationship between circulating levels of $\mathrm{Cr}$ and particularly Co and lymphocyte counts. Metal wear debris, generated at the rate of 1 million, $40 \mathrm{~nm}$ particles per step walked ${ }^{21}$ (active patients walk up to 3 million steps per year ${ }^{22}$ ) may reduce circulating lymphocyte numbers, possibly by diverting these cells out of the circulation, although more likely by interfering with antigen presentation to lymphocytes and their subsequent expansion. The wear debris is generated as a nanoparticle with a high surface are ${ }^{23}$ which is likely to be in equilibrium with its constituent metal ions in solution (Co and $\mathrm{Cr})$. Indeed, some preliminary evidence suggests that there is linearity between whole blood and urine levels of these metal ions indicating that, in the circulation, the metal is present as a soluble species or particles which are much smaller than when first generated, initially $40 \mathrm{~nm}$ in diameter although the renal glomeruli have a pore size of $5 \mathrm{~nm}$. The plasmarisation step of inductively-coupled plasma mass spectrometry in which the sample may be heated to $9000^{\circ}$ Kelvin, helps to ensure that the sample reaching the inductively-coupled plasma is reduced to ionised atoms before reaching the detector. Thus metal nanoparticles and soluble species are not distinguished by this technique. Support for soluble metal species as the active moiety affecting lymphocyte counts comes from in vitro studies showing that they are toxic to lymphocytes. ${ }^{24,25}$

In spite of variation in previous reports on values for circulating $\mathrm{Co}$ and Cr levels in MOM patients, recent carefully-controlled analyses agree that median levels of $1.7 \mathrm{ppb}(\mathrm{Co})$ and $2.3 \mathrm{ppb}(\mathrm{Cr})$ are typical for MOM whole blood, and thus tenfold higher than the median levels in control subjects. ${ }^{17}$ The blood sampling method, laboratory equipment and standard operating procedures used in both the original series and in this large follow-up study were identical with the exception of the method of analysis for blood Co. The relationship between whole-blood $\mathrm{Co}$ and $\mathrm{Cr}$ is not linear but follows a second-order relationship in that the ratio between $\mathrm{Co}$ and $\mathrm{Cr}$ is different at low levels from that at high levels. This could be a result of differential rates of metabolism and saturation of elimination mechanisms.

We currently have no obvious clinical evidence that the reduction in the T-lymphocyte count found in MOM patients is detrimental, although this has yet to be investigated. In fact, it is possible that a reduction in certain T-cell subsets, such as expansions of certain CD $8^{+} \mathrm{T}$-cells to common persistent viral infections, for example cytomegalovirus, may relatively increase overall mortality in the elderly. ${ }^{26-28}$ It has been proposed that MOM patients have reduced mortality compared with healthy control subjects. ${ }^{29}$ Moreover, there is evidence in rodents that very low-dose Cr nanoparticles are beneficial. ${ }^{30}$ Overall, however, no study has determined a safe or toxic dose of Co or $\mathrm{Cr}$ in man. Further work is required to determine the longterm implications, whether beneficial or detrimental, of elevated $\mathrm{Co}$ and $\mathrm{Cr}$ levels in patients with MOM articulations and to establish safe upper limits.

This is the first report in man of a direct link between the level of $\mathrm{Co}$ and $\mathrm{Cr}$ ions in blood and the numbers of circulating lymphocytes. Long-term studies are needed to determine whether the moderate lymphopenia associated with 'high' levels of Co or Cr after the insertion of metal implants are detrimental or even beneficial to longevity. An urgent analysis of current registries of patients with hip implants should provide a useful preliminary answer to this question.

The authors wish to thank P. Tarrassoli, P. Buddhev and C. Patel for the help with the collection of data. We are also grateful for the technical help provided by F. Tahami (Immunology Laboratory, Royal Free Hospital. London).

Funding for this study was provided by the Furlong Research Foundation and Stryker UK Ltd (for the ceramic-on-ceramic cohort).

The author for one more of the authors have received or will receive benefits for personal or professional use from a commercial party related directly or indirectly to the subject of this article.

\section{References}

1. Treacy RB, McBryde CW, Pynsent PB. Birmingham hip resurfacing arthroplasty: a minimum follow-up of five years. J Bone Joint Surg [Br] 2005;87-B:167-70.

2. Heilpern GNA, Shah NN, Fordyce MJF. Birmingham hip resurfacing arthroplasty: a series of 110 consecutive hips with a minimum five-year clinical and radiological follow-up. J Bone Joint Surg [Br] 2008;90-B:1137-42

3. United States Food \& Drug Administration F. New device approval: Birmingham hip resurfacing P040033 9 May 2006. 2006 accessible from http://www.fda.gov/ cdrh/mda/docs/p040033.html (date last accessed 24 February 2009).

4. United States Food and Drug Administration F. New device approval: Cormet hip resurfacing P050016 3 July 2007 accessible from http://www.fda.gov/cdrh/mda/ docs/P050016.html (date last accessed 24 February 2009).

5. Ladon D, Doherty A, Newson R, et al. Changes in metal levels and chromosome aberrations in the peripheral blood of patients after metal-on-metal hip arthroplasty. J Arthroplasty 2004;19(8 Suppl 3):78-83.

6. Hart AJ, Hester T, Sinclair K, et al. The association between metal ions from hip resurfacing and reduced T-cell counts. J Bone Joint Surg [Br] 2006;88-B:449-54.

7. Schaberg T, Theilacker C, Nitschke OT, Lode H. Lymphocyte subsets in peripheral blood and smoking habits. Lung 1997;175:387-94.

8. Huppert FA, Solomou W, O'Connor S, et al. Aging and lymphocyte subpopulations: whole blood analysis of immune markers in a large population sample of healthy elderly individuals. Exp Geronto/ 1998;33:593-600.

9. Uppal SS, Verma S, Dhot PS. Normal values of CD4 and CD8 lymphocyte subsets in healthy indian adults and the effects of sex, age, ethnicity, and smoking. Cytometry $B$ Clin Cytom 2003;52:32-6

10. Bratescu A, Teodorescu $\mathbf{M}$. Circannual variations in the $B$ cell/T cell ratio in normal human peripheral blood. J Allergy Clin Immunol 1981;68:273-80

11. Mazzoccoli G, Bianco G, Correra $\mathbf{M}$, et al. Circadian variation of lymphocyte subsets in health subjects. Recenti Prog Med 1998;89:569-72 (in Italian).

12. Khan M, Takahashi T, Kuiper JH, et al. Current in vivo wear of metal-on-metal bearings assessed by exercise-related rise in plasma cobalt level. J Orthop Res 2006;24:2029-35.

13. Clarke MT, Lee PT, Arora A, Villar RN. Levels of metal ions after small- and largediameter metal-on-metal hip arthroplasty. J Bone Joint Surg [Br] 2003;85-B:913-17. 
14. Back DL, Young DA, Shimmin AJ. How do serum cobalt and chromium levels change after metal-on-metal hip resurfacing? Clin Orthop 2005;438:177-81.

15. Hart AJ, Adam J, Skinner JA, Muirhead-Allwood SK. Component malposition in patients with very high metal levels following hip resurfacing. Procs 75th Annual Meeting, AAOS 2008.

16. Hart AJ, Buddhev P, Winship P, et al. Cup inclination angle of greater than 50 degrees increases whole blood concentrations of cobalt and chromium ions after metal-on-metal hip resurfacing. Hip Int 2008;18:212-19.

17. Winship PD, Faria N, Skinner JA, Hart AJ, Powell JJ. The determination of cobalt and chromium in whole blood sampled from metal-metal and metal-polyethylene hip articulation patients by DRC-ICP-MS. In: Collery P, ed. Metal ions in biology and medicine. Vol. 10. Corsica: John Libbey Eurotext, 2008:27-33.

18. Della Valle CJ, Nunley RM, Raterman SJ, Barrack RL. Initial American experience with hip resurfacing following FDA approval. Clin Orthop 2009;467;72-8.

19. Savarino L, Granchi D, Ciapetti G, et al. Effects of metal ions on white blood cells of patients with failed total joint arthroplasties. J Biomed Mater Res 1999;47:543-50.

20. Granchi D, Savarino L, Ciapetti G, et al. Immunological changes in patients with primary osteoarthritis of the hip after total joint replacement. J Bone Joint Surg [Br] 2003;85-B:758-64

21. Anissian HL, Stark A, Good V, Dahlstrand H, Clarke IC. The wear pattern in metal-on-metal hip prostheses. J Biomed Mater Res 2001;158:673-8.
22. Sechriest VF 2nd, Kyle RF, Marek DJ, et al. Activity level in young patients with primary total hip arthroplasty: a 5-year minimum follow-up. J Arthroplasty 2007:22:39-47.

23. Catelas I, Bobyn JD, Medley JB, et al. Size, shape, and composition of wear particles from metal-metal hip simulator testing: effects of alloy and number of loading cycles. J Biomed Mater Res A 2003;67:312-27.

24. Granchi D, Cenni E, Ciapetti G, et al. Cell death induced by metal ions: necrosis or apoptosis? J Mater Sci Mater Med 1998:9:31-7.

25. Granchi D, Ciapetti G, Savarino L, et al. Assessment of metal toxicity on human lymphocytes cultured in vitro. J Biomed Mater Res 1996;31:183-91.

26. Ouyang Y, Wagner WM, Zheng W, et al. Dysfunctional CMV-specific CD8(+) T cells accumulate in the elderly. Exp Gerontol 2004;39:607-13.

27. Pawelec G, Gouttefangeas C. T-cell dysregulation caused by chronic antigenic stress: the role of CMW in immunosenescence? Aging Clin Exp Res 2006;18:171-3.

28. Vasto S, Colonna-Romano G, Larbi A, et al. Role of persistent CMW infection in configuring T cell immunity in the elderly. Immun Ageing 2007;4:2

29. No authors listed. National Joint Registry UK, 5th Annual Report. www.njrcentre.org.uk. (date last accessed 10 May 2009).

30. Zha LY, Xu ZR, Wang MQ, Gu LY. Effects of chromium nanoparticle dosage on growth, body composition, serum hormones and tissue chromium in Sprague-Dawley rats. J Zheihiang Univ Sci B 2007;8:323-30. 